\title{
FACTORS AFFECTING THE FLOATING AQUATIC FEED PELLETS QUALITY
}

\author{
Kaddour, O."
}

\section{ABSTRACT}

Production of high quality floating aquatic feed has in recent years accounted more than 65\% of the market needs of fish feed. Most of fish feed factories have tended to develop their production lines by adding extrusion units to produce floating fish feed after increasing demand from farmers for this type of feed for many reasons, such as :the high conversion rates than sinking feed, decreased the consumed amounts of fish feed in aquaculture farms about 30\%,easy to follow the fish vitality during feeding process and reduced the chances of infection by fish diseases. The parameters under studied were water addition site (just preconditioner- just extruder barrel zones -pre-conditioner and extruder barrel zones), extruder screw configurations profile (high configuration shear, medium configuration shear and low configuration shear) and drying cooling process after extrusion (cooling only and drying with cooling). Steam percentage of (13\%) added into the pre-conditioner for all study treatments as constant parameters. The floating die specifications of the extruder were $L / D$ ratio of 30:1, land length diameter of $2.5 \mathrm{~mm}$ and the die consists of 10 holes each outer diameter of $2.5 \mathrm{~mm}$. The optimum running parameters for proceeds floating aquatic feed were water addition into both pre-conditioner and extruder barrel zones $(9 \% P C+5 \% E X)$, high shear screw configurations profile, and drying process for $10.5 \mathrm{~min}$ at air temperature of $210^{\circ} \mathrm{C}$ with cooling process for $5.5 \mathrm{~min}$. The result of extruder performance and floating pellets quality measurements for these parameters were, extruder production rate of $196.6 \mathrm{~kg} / \mathrm{h}$, extruder specific mechanical energy (SME) of $130.7 \mathrm{~kJ} / \mathrm{kg}$, floating pellets bulk density of $332.9 \mathrm{~kg} / \mathrm{m3}$, final product pellets expansion ratio of 2.28 , and floating pellets water stability of $100 \%$ after $33 \mathrm{~h}$ in water.

\section{*Associate professor- Engineering Sciences Department -Faculty of fish resources - Suez University,}




\section{INTRODUCTION}

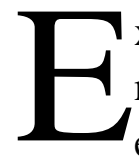

xtrusion technologies become one of the important process in many kind of industries, it called extrusion art that is because the extruder is very sensitive machine and the products affected by several physical and mechanical factors, slight changing in this factors give different product, so the operator of the extruder should be professional to can control the extruder performance. The application of the extruder can be summarized in three axes such as utilizing the extrusion as feed, as food and as industries. Riaz (2000) reported the functions of extrusion process, such as expansion, gelatinization, mixing, dehydration, degassing, texture, grinding, homogenization, thermal cooking, shearing, shaping, and protein denaturation. Extrusion has unlimited possibilities of applications as food the production of pasta, snacks, breakfast cereals ,as feed such as aquatic feed, marine fish feed, pet food and as industries such as plastics production, forming and Cellulose cracking for ethanol production. There are two types of the extruders, single screw extruder and twin screw extruder, the main advantages of the single screw extruders are simple mechanically, easier in maintenance, use for oily products like aquatic feed and low price and cost than twin screw extruders that used on a large scale in food industries. All the types of extrusion theory depends on heat and thermal generation from shearing of the formulations gradually through the extruder barrel zones from feeding zone to die zone. Many factors affecting the extruder performance and product quality such as moisture content, raw material particle size and viscosity as physical factors, screw configurations, screw speed, screw LID ratio, die holes profiles, die holes opening area, material retention time in pre-conditioner and feeding rate as mechanical factors. Also the processing after extrusion such as drying and cooling profiles. (Rosato et al., 2003) Reimer (1992) accounting that $60 \%$ of pellets product quality is influenced by all the pelleting or extrusion mechanical factors. Only $40 \%$ of products quality influenced by the pellet mill or extruder parameters, $20 \%$ from the $40 \%$ the conditioning process and retention time, $15 \%$ affecting by the die profile and specification and the last $5 \%$ is due to drying and cooling profile of the final pellets product. The extruder screw L/D ratio has different ratios 
depends on the extruder geometrical design and application of extrusion and product. Extruders used as feed the L/D ratios maximum20: 1, expanded products extruder screws has L/D ratios maximum 9: 1 with a screw diameter range $120-200 \mathrm{~mm}$. otherwise, the L/D ratio of 30 used for cooking and forming. (Miller and Mulvaney, 2000). Low shear stress screw profiles using in forming extruders for high density materials, high moisture content and have a big L/D ratio "which generated low mechanical energy (SME).

Expanded products like floating aquatic feed and pet food are produced by high shear stress screw profile extruders, which have the small L/D ratios. Extruder dies has different profiles depends on the products such as number of hole, holes output diameter, the holes dimensions of entry and land length and holes shape. This dies profiles control the product final shape, density and expansion ratio Chevanan et al. (2010) studied the effect of die holes dimensions and profile as one of extrusion parameters and the properties of DDGS. He found that the simple die holes design' the annular openings the most common shape in feed products. Fang et al. (2003b) indicated that, extruder feeding rate depends on the screw speed, screw configurations, extruder feeding system, and feed formulation moisture content. Feeding rate has an effect on retention time, extruder torque, extruder barrel pressure and formula temperature. Kokini et al., (1992) said that, extruder barrel and screws divided to many zones, first zone is feeding zone has low temperature, the material moved to the die and cooking zones with increasing in material temperature and barrel pressure, Barrel temperature has a high effect on the starch gelatinization degree and product expansion ratio, the increase in barrel temperature make direct change in material color, however the high temperature lead to remove high percentage of material temperature after cooking and increase the pellets expansion ratio. Lundblad et al.,(2008) found that steam conditioning processing commonly used in pelleting and extrusion operating to added moisture and heat to the formulation, the benefits of temperature during the pelleting process to decreased the bacteria and increase the product quality quality. Otherwise, moisture is important for increase the gelatinization degree of starch and denaturation of proteins. Particle size also plays an important affect in extrusion process not only in heat transfer, viscosity and moisture 
distribution, but also in final product quality. The ingredient particles size increase the screws and barrel wearing than fine particles, the fine particles formula indicate for best water stability product composed of will have good water stability, expansion ratio, and floatability. A better understanding of the interactions between the extruder and ingredients within the barrel facilitates the development of not only screw and barrel configurations for converting mechanical energy to heat through friction but also new products ,but many factors are important (Caldwell et al.2000), Behnke (1994) stated that grinding the formula to fineness degree influence on pellet best quality .extrusion lines has two milling stages to pass the very fine formulation to extruder and give better the pellet quality .Particle size affects both the extend of conditioning and the way in which particle bonding occurs in the pellet itself .In terms of pellet mill operations, the conditioning process has greater influence on pellet quality than does die specification. The aim of this study that determine of the optimum of physical and mechanical factors that affecting the extruder performance and floating aquatic feed quality to help the feed sectors to produce the high quality feed with low cost

\section{MATERIALS AND METHODS}

\section{Material:}

\section{Composition of the floating aquatic feed formula:}

A fish feed floating experimental formula was used in the present study, the composition of the formula were corn flour $28 \%$, wheat flour 18 $\%$,soy bean $25 \%$,fish meal $16 \%$, shrimp meal $10 \%$, premix $2 \%$ and fish oil $1 \%$, the particle size of the formula were $0.8 \mathrm{~mm}$.

\section{Equipment list:}

1-Wenger X-20 single screw extruder system and DDC pre-conditioner system, Sabetha, KS:The specification of the extruder that used to produce floating aquatic feed pellets were different screw configuration of low, medium and high shear screw profile. The constant conditions were:

A-Raw material and feeding system constant condition, were for raw material: moisture $11.1 \%$, bulk density of $523.4 \mathrm{kglcm}^{3}$, formula particle size were $0.8 \mathrm{~mm}$. Feed temperature of $21 \mathrm{C}^{\circ}$, feed rate of $205.33 \mathrm{~kg} \mathrm{hh}$ and feed screw speed of 19.9 RPM. 
B- pre-conditioner constant condition: were shaft speed of 400RPM, steam flow $20.20 \mathrm{kghh}$, water flow of $14.4,23.0$ and $0.0 \mathrm{kghh}$ and discharge temperature of $92 \mathrm{C}^{\circ}$.

C- Extruder constant condition: screw speed 299 RPM, steam flow 9.0, 0.0 and $23.0 \mathrm{~kg} \backslash \mathrm{h}$, water flow of $8.20,0.0$ and $23.0 \mathrm{~kg} \backslash \mathrm{h}$, head pressure of 7.3 PSIG and extruder set temperature of 80,90 and $100 \mathrm{C}^{\circ}$ for zone 1,2 and 3, respectively. Different extruder screws configuration used to make different shear inside the extruder barrel to increase the pressure and formula temperature (Fig

2-Die holes profile: Back up die No (68347-7) and die holder No (55375-122),holes profile designed and manufactured in winger workshop were (land length of $2.5 \mathrm{~mm}$; die hole entry diameter of $7.52 \mathrm{~mm}$, number of holes 10 , output area of $49.06 \mathrm{~mm}^{2}$, die L/D ratio was 30: 1, with die hole outlet diameter of $2.5 \mathrm{~mm}$.(Fig2 And B).

(A)

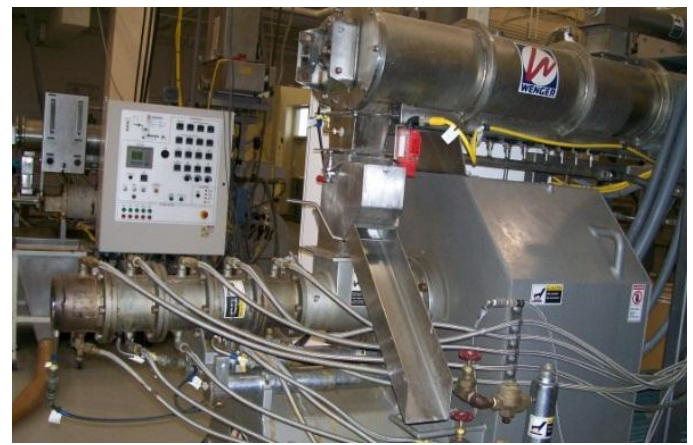

(B)

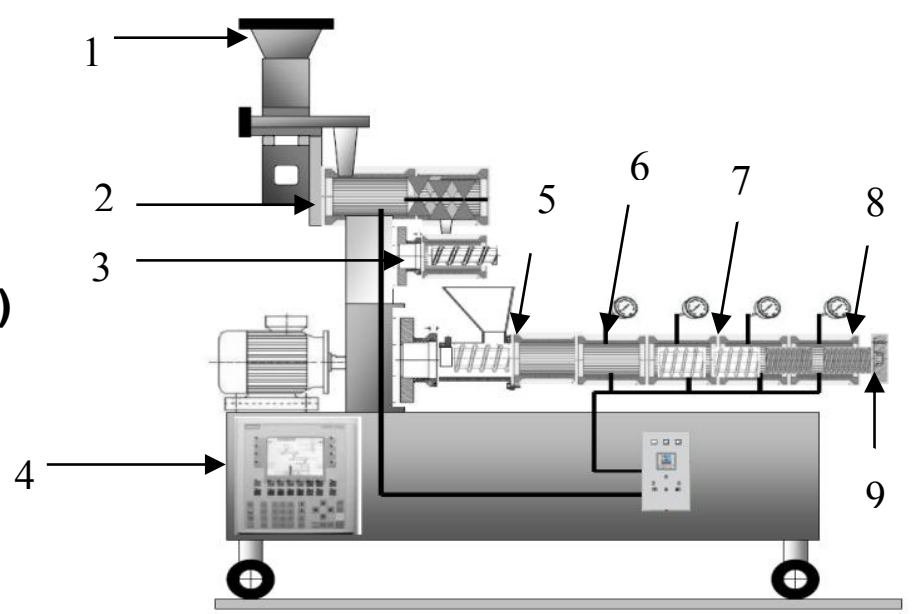

1-Extruder bin

2- Pre-conditioner 3- Feeding system 4-Electric control unit 5-Barrel feeding zone 6Barrel kneading zone 7-Barrel cooking zone

8-Barrel die zone 9- Forming unit (Die)

Fig.(1A and B) A Picture of Wenger X-20 single screw extruder system and DDC pre-conditioner system, Sabetha, KS, B a Cross section on the single screw extruder 
3-Wenger Gas-fried dryer series 4800 (two pass dryer, one pass cooler), Sabetha, KS.

4-Wenger batch mixer 5.5 HP (ribbon mixer stainless steel material)

5-Pneumatic lift system to convey product from extruder to dryer.

6- Weighing scale (Kubota), other scale used for bulk density and durability measurements (Ranger Ohaus, Topeka)

7-Moisture content instrument Dnever IR-200(moisture content measurement unit).

8- Stop watch Casio FX53

(Fig2)

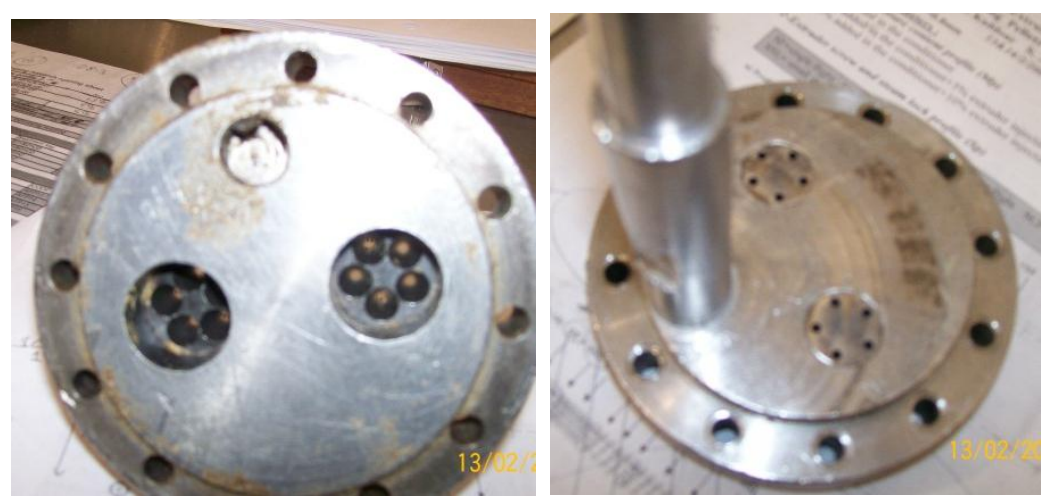

\begin{tabular}{|c|c|c|c|c|}
\hline $\begin{array}{c}\mathbf{N} \\
\text { (holes) }\end{array}$ & $\begin{array}{c}\text { Dhe } \\
(\mathrm{mm})\end{array}$ & $\begin{array}{c}\text { At } \\
\left(\mathrm{mm}^{2}\right)\end{array}$ & $\begin{array}{c}\mathbf{L} \\
(\mathrm{mm})\end{array}$ & $\begin{array}{c}\mathrm{A} \mathrm{h} \\
\left(\mathrm{mm}^{2}\right)\end{array}$ \\
\hline 10 & 7.52 & 49.06 & 2.5 & 4.9 \\
\hline
\end{tabular}

(Fig3)

$$
\rightarrow L \mid-
$$

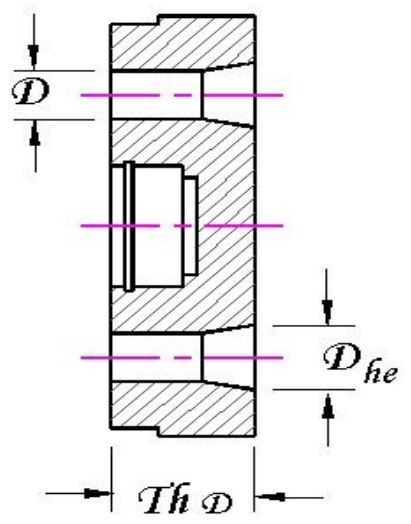

Section $C-C$

Fig. (2 and 3)Wenger X-20 single screw extruder Sabetha, KS die profile and die holes dimensions. 


\section{METHODS:}

\section{Processing Parameters:}

Floating feed formula was extruded by Wenger X-20 single screw extruder system and DDC pre-conditioner system, Sabetha, KS, to study the physical and mechanical factors affecting the Tilapia floating feed pellets quality .The process parameters were:

\section{1-Extruder screw profile (Three configurations):}

\section{From feeding zone to Die zone}

High shear (S1) - Medium shear (S2) and Low shear (S3)

$S 1=S F+S F+S S L+S F+S S L+S F+M S L+D F+L S L+D C F$

$S 2=S F+S F+S S L+S F+S S L+D F+M S L+D F+L S L+D F$

$S 3=S F+S F+S S L+S F+S S L+S F+S S L+S F+M S L+D F$

Where:

$\mathrm{SF}=$ single flight $-\mathrm{DF}=$ double flight $-\mathrm{DCF}=$ double cut flight

$\mathrm{SCF}=$ single cut flight $\quad \mathrm{SSL}=$ small steam lock $\quad$ LSL $=$ large

steam lock - MSL= medium steam lock

\section{2- The moisture and steam profile:}

$M 1=13 \%$ steam $P C+9 \%$ water $P C+5 \%$ water $E X$

$M 2=13 \%$ steam $P C+14 \%$ water $P C+0 \%$ water $E X$

$M 3=13 \%$ steam $P C+0 \%$ water $P C+14 \%$ water $E X$

Where:

M1, M2 and M3 Moisture profiles

$\mathrm{PC}=$ Pre- conditioner $\quad \mathrm{EX}=$ Extruder position

\section{3- Drying and cooling Profile}

$1-D C=($ Drying $10.5 \mathrm{~min} 210 \mathrm{cO}+$ cooling 5.5 min cooled air $)$

2- $C=($ Just cooling 5.5 min cooled air $)$

\section{Evaluation of floating pellet quality Performance:}

The experimental study running and collecting the sample, data analysis for aquatic feed Tilapia pellets were produced by a single screw extruder using dies with $2.5 \mathrm{~mm}$ diameter circular openings. The extruder factors performance was evaluated for extruder efficiency and pellets quality based on the following measurements: 1-Extruder production rate 2- 
Specific mechanical energy (SME), 3- floating Pellet bulk density, 4pellet expansion ratio 5-Pellets water stability.

1- Extruder production rate was measured for each treatment by taking sample for 2 min after 15 min. of extruder running.

2- Specific mechanical energy (SME), was calculated using the following relation:

$$
\mathrm{SME}=\{(\% \mathrm{~T}-\% \mathrm{~T} 1) * \text { Power } \mathbf{k W}(\mathrm{N} / \mathrm{N} 1)\} / \mathrm{M} \mathrm{kg} / \mathrm{s}
$$

Where: $(\mathrm{SME})=$ specific mechanical energy.

$\mathrm{T}=$ Motor load $\%$ in load

$\mathrm{T} 1=$ Motor load without load \% (0.05) N= Screw speed rpm, N1:

Valid screw speed RPM (500 rpm) and M= Production rate $\mathrm{kg} / \mathrm{s}$

3- Pellet bulk density was calculated using Standard method of Feed Manufacturing (American Feed Industry Association, Inc., 2000).

4- Pellet expansion ratio was calculated by measuring the pellet diameter after extruded using the formula

$$
S E I=\frac{D_{e}{ }^{2}}{D_{d}{ }^{2}}(\text { ratio })
$$

Where De: Extruded pellet diameter Dd: Die hole diameter

5- Pellet water stability was calculated by put the pellet in glass water and measure the number of pellet still stable in water after ( start,15, 30,45 min, 1 , 3 , 6,12 and 24 hour) using formula:

\section{Pellet water stability $=\mathbf{N}_{\text {st }} 1 \backslash \mathbf{N}_{p} \times 100$}

Where Nst: Number of stable pellets in the water

$\mathrm{N}_{\mathrm{t}}$ : Total pellets sample.

\section{RESULTS AND DISCUSSION}

\section{1-Extruder production rate:}

The screw profile the most important mechanical factors affecting the floating extruder pellets production. The effect of extruder screw profile moisture content percentage in formula and drying cooling profile showing in Fig(4), it's clear to see the screw profile affecting the extruder 
production rate from low shear profile to medium and high shear .change the screw profile from high shear (profile1) to medium shear (profile2) and low shear (profile3) increased the extruder productivity from 197,0 to $r \cdot r, \cdot r$ and $212.94 \mathrm{kglh}$ at moisture profile 1, 2 and 3 with cooling only and same result with drying and cooling profile, from result we can see clear there are no significant affection for changing the moisture content or changing the drying and cooling profile on extruder production rate.

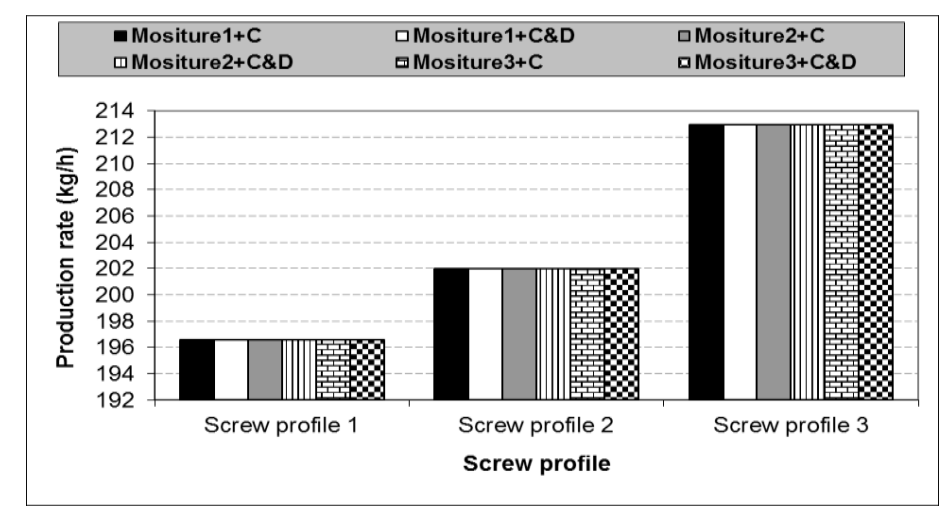

Fig. (4): Effect of screw profile, moisture content profile and cooling and drying with cooling on production rate.

The increasing of extruder production rate by change the screw profile from high shear (profile1) to medium shear (profile2) and low shear (profile3) that could do due to the increasing of pellets expansion ratio and decrease the pellets bulk density using high shear because the high shear meaning the higher extruder mechanical pressure and temperature that lead to increase the starch gelatinization and increase the air bubblies in pellets.

\section{2-Extruder specific mechanical energy (SME):}

Specific mechanical energy (SME) one of important measurement for producing best quality aquatic feed with low (SME) the target of the feed mill plant. Extruder screw profile meaning the screw configurations on the extruder main shaft from feeding zone to die zone, as we know change the screw flight from single flight to double flight that is mean increase the mechanical pressure and temperature by fraction. Data showed in Fig (5) give us indicate for the effect of screw profile in (SME), change the screw 
profile from high shear (profile1) to medium shear (profile2) and low shear (profile3) decreased the (SME) from130.72 to and $105.58 \mathrm{~kJ} k g$ at moisture profile1, from 134.81 to 131.17 and $109.36 \mathrm{~kJ} / \mathrm{kg}$ at moisture profile 2 and from 130.73 to 127.19 and $105.58 \mathrm{~kJ} \mathrm{~kg}$ at moisture profile3using dying and cooling and just cooling, from data we can see the moisture profile affecting the (SME) moisture profile1 add the water in pre-conditioner and extruder barrel decreased the (SME) around 3\% than add the total water amount in pre-conditioner as in moisture profile 2.in same data showed, no any affect for drying and cooling profile in (SME).

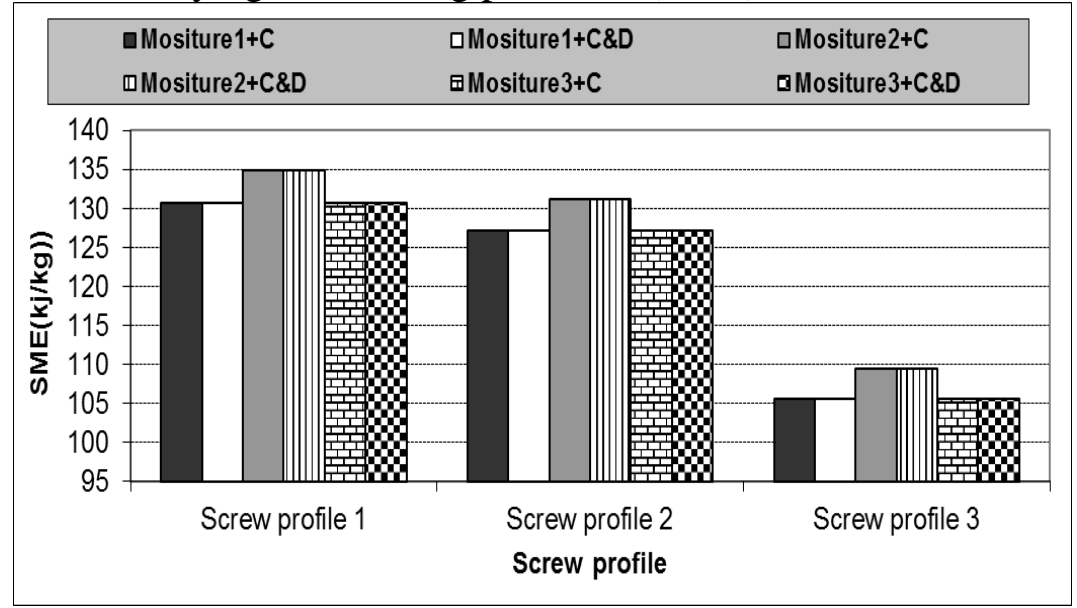

Fig (5): Effect of screw profile, moisture content profile and cooling and drying with cooling on specific mechanical energy (SME).

The decrease in (SME) by change the screw profile from high shear to medium and low shear that could be due to the decrease in mechanical pressure by increase the screw pitch that lead to decrease the fraction between the formula and extruder barrel and that lead to decrease the motor load and power consumption and increase the treatment production rate. Otherwise adding the water in both of extruder pre- conditioner and barrel or just in extruder barrel decreased the (SME) that could be due to the decrease of machine and motor load and increase the productivity. On another hand there is no any effect for drying and cooling profile in (SME) that is because drying and cooling treatment after extrusion the formula.

\section{3- Pellet bulk density:}

Aquatic feed bulk density one of the quality control measurements for extruder fish feed plants, bulk density affecting the pellets floating 
percentage, pellets water stability and final product bag size. Data in Fig (6) showed indicated that the effect of screw profile in (SME), change the screw profile from high shear (profile1) to medium shear (profile2) and low shear (profile3)increased the pellets bulk density from 340.4 to 363 and $391 \mathrm{~kg} \backslash \mathrm{m}^{3}$, from 365.6 to 398.3 and $449.1 \mathrm{~kg} \backslash \mathrm{m}^{3}$ and from 352.6 , 382.6 and $420.9 \mathrm{kglm}^{3}$ using moisture profile of 1,2and 3 respectively with just cooling profile after extruder. Same trend data showed by using the drying and cooling process, the bulk density increased from 332.9 to 358.4 and $384.8 \mathrm{~kg} \backslash \mathrm{m}^{3}$, from 354.7 to 387.4 and $437.6 \mathrm{kglm}$ and from 343 to 370.6 and $410.1 \mathrm{kglm}^{3}$ using moisture profile of 1,2 and 3 respectively.

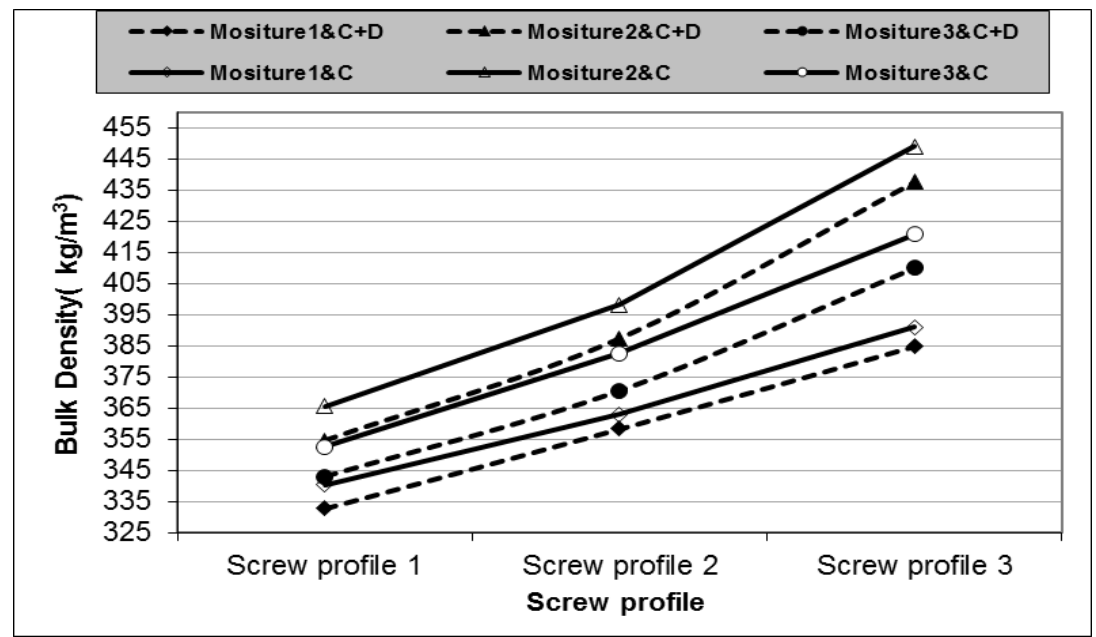

Fig (6): The effect of extruder screw profile, moisture profile and drying cooling profile on pellets bulk density.

Regarding to the effect of moisture content profile data in same figure showed that add the $14 \%$ water in both of pre-conditioner and extruder barrel give us the lowest bulk density while when we add the moisture just in pre-conditioner give us the higher bulk density, otherwise add the moisture in just extruder barrel give us medium bulk density, with all of extruder screw profiles and drying cooling profiles. It were 340.4, 365.6 and $352.6 \mathrm{kglm}$ using screw profile shear 1 (high shear) and just cooling profile. The effect of drying cooling profile on final product bulk density data in Fig (6) reported that using the drying and cooling profile decreased the pellets bulk density comparing with using just cooling 
process after extruder with all screw profiles and moisture profiles, it decreased from 340.4 to $332.9 \mathrm{~kg} \mathrm{~mm}^{3}$ using screw profile 1(high shear) with moisture profile 1 , decreased from 398.3 to $387.4 \mathrm{~kg} \backslash \mathrm{m}^{3}$ using screw profile 2(medium shear ) with moisture profile 2 and decreased from 420.9 to $410.1 \mathrm{~kg} \mathrm{~m}^{3}$ using screw profile 3(low shear) with moisture profile 3.

The above data show clearly the extruder screw shear affecting the final product bulk density more than the moisture profile and drying cooling profile, the decrease in pellets bulk density by using high shear more than medium and low shear could be due to the increase in mechanical pressure that lead to increase in pellets expansion and diameter add to the increase in air bubblies in pellets all this reasons decrease the density of pellets and increase the pellets volume. Otherwise the moisture profile affecting the bulk density slightly but clear too see add the $14 \%$ of moisture in extruder pre-conditioner increased the product bulk density that could be due to added the moisture in extruder barrel increase the cooking process of fish formula and that help to complete the starch gelatinization process .meanwhile added the moisture in just preconditioner lead to decrease the expansion and cooking of formula and increase final product bulk density. On the other hand, the drying and cooling the process profile decreased the bulk density more than just cooling profile process and that could be due to the drying processing lead to evaporate the free moisture between the formula granules so decrease the pellets mass and pellets bulk density.

\section{4- Pellet expansion ratio:}

The theory of floating fish feed production is based on the exposure of fish feed formula that contents of starch for high-pressure and hightemperature inside the extruder barrel, that lead to complete the starch gelatinization process, which leads to the generation of air cells and changes in the product diameters larger than the diameters of the die holes. It's very important for any aquatic feed plant know the optimum expansion ratio that give us indicate of the floating percentage and time and the pellets density suits to the bagging size. Data in Fig (7) showed that the effect of screw profile on expansion ratio, change the screw 
profile from high shear (profile1) to medium shear (profile2) and low shear (profile3) decreased the expansion ratio from 2.45 to 2.32 and 2.22 at moisture profile 1 , from 2.4 to 2.27 and 2.2122 at moisture profile 2 and from 2.45 to 2.3 and 2.2 at moisture profile 3 , using just cooling profile. Data give same indicate of change screw profile using drying and cooling profile, the expansion ratio decreased from 2.27 to 2.2 and 2.11 at moisture profile 1 , from 2.2 to 2.14 and 2.1 at moisture profile 2, and from 2.23 to 2.18 and 2.1 at moisture profile 3 . While, the effect of moisture profile on product expansion ratio, it's clear to see from data in Fig (7) that adding the moisture in extruder barrel increase the expansion ration than add the $14 \%$ totally in pre-conditioner with all another parameters, screw profiles and drying cooling profiles for example, the expansion ratio increased from 2.4 at moisture profile $2(14 \%$ water in pre-conditioner) to 2.45 at both moisture profile 1 (9\% in preconditioner+5\% in extruder barrel) and to 2.45 at moisture profile3 (14\% in extruder barrel)

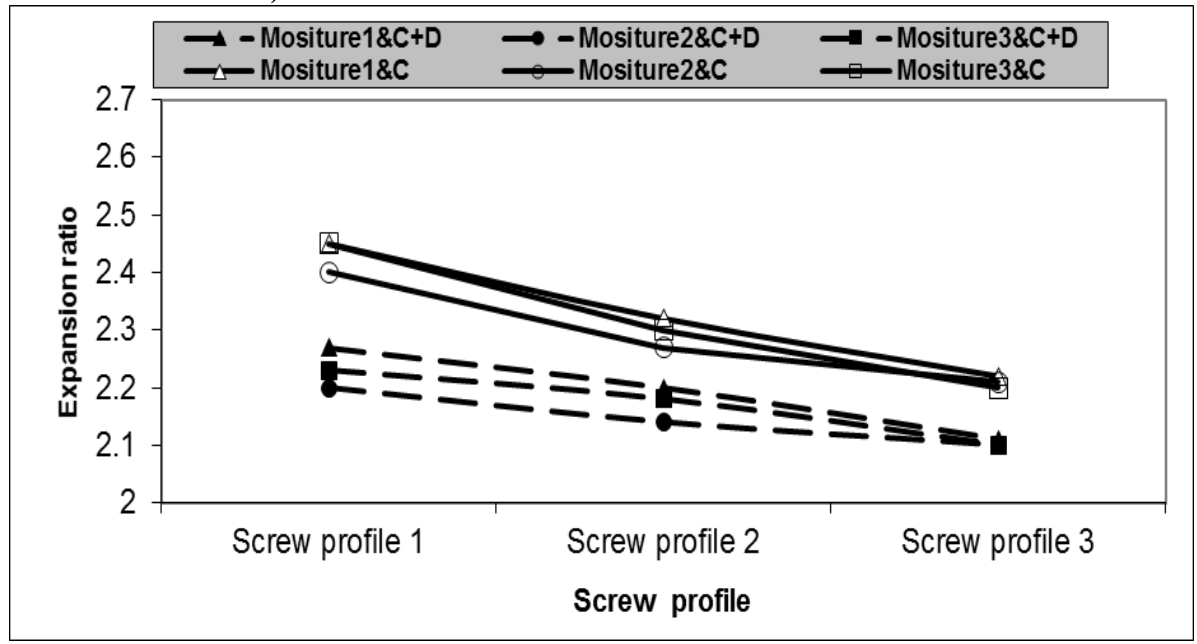

Fig. (7): Effect of extruder screw profile, moisture profile and drying cooling profile on pellet expansion ratio.

Otherwise the effect of drying cooling profiles on pellets expansion ratio, same figure showed the expansion ration decreased by using drying and cooling profile than just use cooling profile treatment with all different screw profiles and moisture profiles, it decreased from 2.45 to 2.27 , from 2.4 to 2.2 and from 2.45 to 2.23 using high shear screw profile 1 and 
moisture profiles 1, 2 and 3 respectively. The scientific interpretation of the previous results can be summarized as follows. The increase in product expansion ratio by changing the screw profile from high shear (profile1) to medium shear (profile2) and low shear (profile3) could be duo to the reduce of extruder shear, pressure and temperature that causes decrease in starch gelatinization ratio and product diameters. However adding the moisture in extruder barrel increase the expansion ration than add the $14 \%$ totally in pre-conditioner that could be due to the moisture in extruder barrel zones most important to increase the formula cooking, so increase the formula flow from feeding zone to die zone with gradually increase in gelatinization ratio and product diameters. Meanwhile add the moisture just in pre-conditioner lead to bulky flow of formula through the extruder zones and decrease the formula cooking and expansion ratio. On other hand the expansion ration decreased by using drying and cooling profile than just use cooling profile treatment that could be due to the drying process remove the free moisture between the pellets granules and that leads to decline the air cells and pellets diameter clipping

\section{5-Pellets water stability:}

Pellets water stability measuring means the time that aquatic feed pellets can be remains floating in water without collapse, it is one of the methods that farmers use for assessment the aquatic feed quality. Data in table (1) and Fig (8) showed the effect of screw profile using different drying and cooling profiles on pellets water stability, the pellets produced by extruder high shear screws (profile1) the pellets can be $100 \%$ water stability for54 hours at drying and cooling profile and for 33 hours at just cooling profile. While change the extruder screw profile to medium shear (profile2) the pellets can be $100 \%$ water stability for 27 hours at drying and cooling profile and for 18 hours at just cooling profile. Meanwhile change the extruder screw profile to low shear (profile3)the pellets can be $100 \%$ water stability for12hours at drying and cooling profile and for6hours at just cooling profile using moisture profile1(14\% moisture in both of preconditioner and extruder barrel). 
Water stability the most important economic target for the aquaculture farmers, the discussion of obtained data explained the best results for using the extruder screw configurations to control the aquatic feed water stability. The percentage of pellets water stability still $100 \%$ for 54 hours by using high shear screw profile at drying with cooling could be due to the high ratio of starch gelatinization by the maximum mechanical pressure and temperature in die zone of extruder barrel that generated high number and volume of air cells (air bubblies) has a gelatin walls making it so difficult for the water to penetrates the cells wall and replace with the air inside the cells that needs for pellets collapse.

Table (1): The effect of extruder screw profile and drying cooling profile on pellets water stability percentage using moisture profile (1).

\begin{tabular}{|c|c|c|c|c|c|c|}
\hline Start & $\begin{array}{c}\text { Screw } \\
\text { profile1 } \\
\text { C\&D }(\%)\end{array}$ & $\begin{array}{c}\text { Screw } \\
\text { profile2 }+ \\
\text { C\&D }(\%)\end{array}$ & $\begin{array}{c}\text { Screw } \\
\text { profile3 }+ \\
\text { C\&D }(\%)\end{array}$ & $\begin{array}{c}\text { Screw } \\
\text { profile1 } \\
+C(\%)\end{array}$ & $\begin{array}{c}\text { Screw } \\
\text { profile2 } \\
+C(\%)\end{array}$ & $\begin{array}{c}\text { Screw } \\
\text { profile3 } \\
+C(\%)\end{array}$ \\
\hline $3 \mathrm{~h}$ & 100 & 100 & 100 & 100 & 100 & 100 \\
\hline $6 \mathrm{~h}$ & 100 & 100 & 100 & 100 & 100 & 100 \\
\hline $9 \mathrm{~h}$ & 100 & 100 & 100 & 100 & 100 & 94 \\
\hline $12 \mathrm{~h}$ & 100 & 100 & 100 & 100 & 100 & 90 \\
\hline $15 \mathrm{~h}$ & 100 & 100 & 98 & 100 & 100 & 86 \\
\hline $18 \mathrm{~h}$ & 100 & 100 & 64 & 100 & 100 & 59 \\
\hline $21 \mathrm{~h}$ & 100 & 100 & 29 & 100 & 91 & 47 \\
\hline $24 \mathrm{~h}$ & 100 & 100 & 0 & 100 & 90 & 11 \\
\hline $27 \mathrm{~h}$ & 100 & 100 & 0 & 100 & 89 & 0 \\
\hline $30 \mathrm{~h}$ & 100 & 61 & 0 & 100 & 34 & 0 \\
\hline $33 \mathrm{~h}$ & 100 & 11 & 0 & 100 & 0 & 0 \\
\hline $36 \mathrm{~h}$ & 100 & 0 & 0 & 97 & 0 & 0 \\
\hline $39 \mathrm{~h}$ & 100 & 0 & 0 & 62 & 0 & 0 \\
\hline $42 \mathrm{~h}$ & 100 & 0 & 0 & 50 & 0 & 0 \\
\hline $45 \mathrm{~h}$ & 100 & 0 & 0 & 0 & 0 & 0 \\
\hline $48 \mathrm{~h}$ & 100 & 0 & 0 & 0 & 0 & 0 \\
\hline $51 \mathrm{~h}$ & 100 & 0 & 0 & 0 & 0 & 0 \\
\hline $54 \mathrm{~h}$ & 100 & 0 & 0 & 0 & 0 & 0 \\
\hline
\end{tabular}




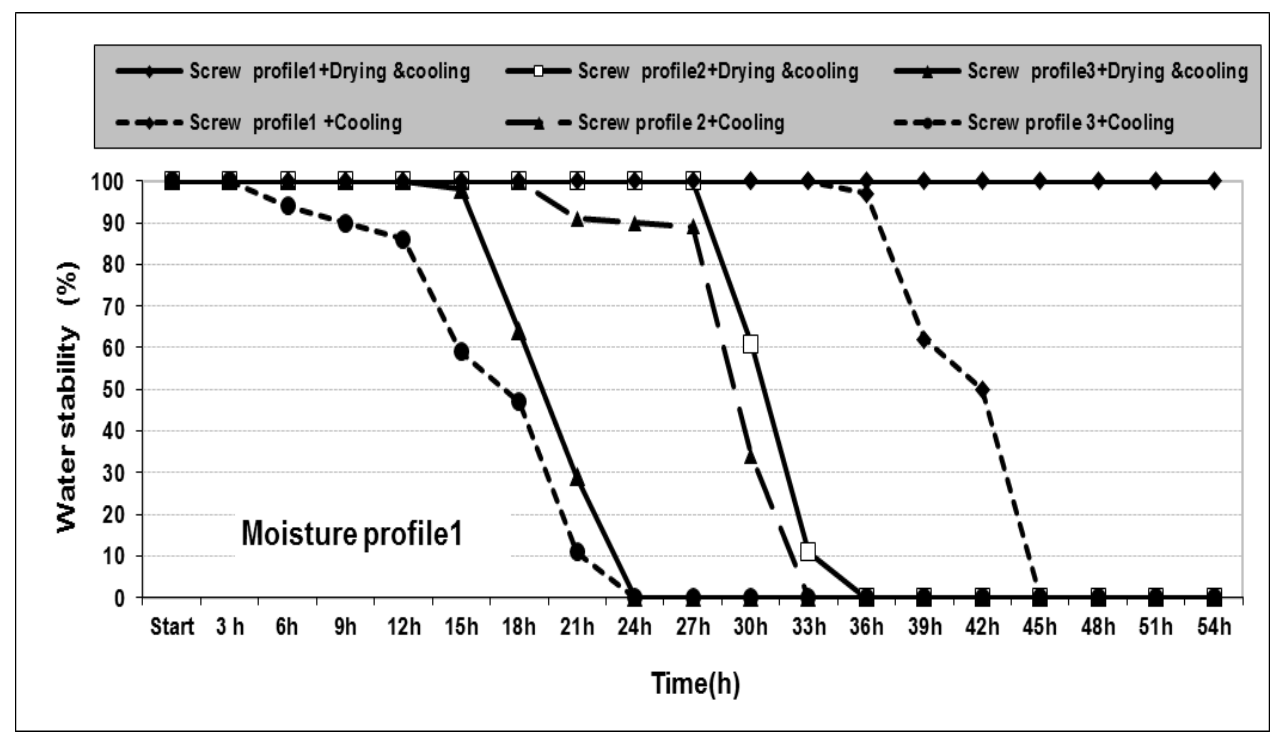

Fig. (8): The effect of extruder screw profile and drying cooling profile on pellets water stability percentage using moisture profile (1)

By the way reduce the extruder screw shear reduce the number and volume of air cells and the gelatin walls so decrease the water stability percentage. Otherwise the increase in water stability time by using drying and cooling profile more than use just cooling process after extruder causes to the drying remove the free moisture between granules and that lead to increase the air cells volume and number. The effect of moisture profile on pellets water stability showed in Fig. (9) The water stability percentage were $100 \%$ for 27 hours using moisture profile1 (14\% moisture in both of pre-conditioner and extruder barrel) reduced to $76 \%$ and $94 \%$ moisture profile2 (14\% moisture in pre-conditioner) and moisture profile3 (14\% moisture in extruder barrel) respectively at screw profile 2and drying cooling profile. The high percentage of pellets water stability after 27 hours by using moisture profile 1 and 3 than moisture profiles 2 could be due to adding the moisture or part of it in extruder barrel zones increase the cooking process and increase the expansion ratio too, that lead to produce more of air cells in pellets and increase the starch gelatinization ratio. 


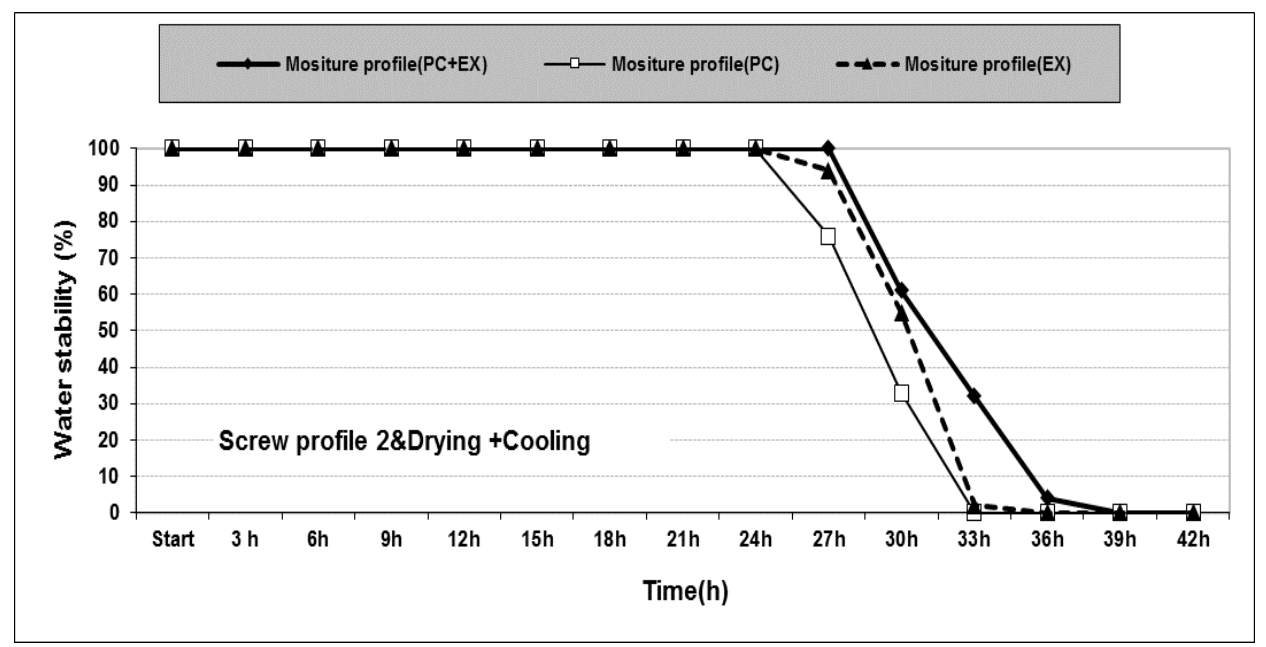

Fig. (9): The effect of moisture profiles on pellets water stability percentage using extruder profile (2) and drying with cooling profile.

\section{CONCLUSION}

Production of high quality floating aquatic feed has in recent years accounted more than $65 \%$ of the market needs of fish feed. Most of fish feed factories have tended to develop their production lines by adding extrusion units to produce floating fish feed after increasing demand from farmers for this type of feed for many reasons, such as :the high conversion rates than sinking feed, decreased the consumed amounts of fish feed in aquaculture farms about $30 \%$,easy to follow the fish vitality during feeding process and reduced the chances of infection by fish diseases. The parameters under studied were water addition site (just preconditioner- just extruder barrel zones -pre-conditioner and extruder barrel zones), extruder screw configurations profile (high configuration shear, medium configuration shear and low configuration shear) and drying cooling process after extrusion (cooling only and drying with cooling). Steam percentage of (13\%) added into the pre-conditioner for all study treatments as constant parameters. The floating die specifications of the extruder were L/D ratio of 30:1, land length diameter of $2.5 \mathrm{~mm}$, and the die consists of 10 holes each outer diameter of $2.5 \mathrm{~mm}$. 
PROCESS ENGINEERING

\section{REFERENCES}

AACC, 2000. Approved Methods of the American Association of Cereal Chemists. Methods 38-12 and 46-13, 10th ed.American Association of Cereal Chemists, St Paul (MN).

Behnke, K.C. (1994). Factors influencing pellet quality. Feed Tech., 5 (4).

Caldwell, E.F., Miller, R.C., Fast, R.B. et al. (2000) Unit operations and equipment I:Blending and cooking. In: Breakfast Cereals and How T hey Are Made, 2nd edn (edsR.B. Fast and E.F. Caldwell). American Association of Cereal Chemists, Inc., St Paul, MN, pp. 55-132.

Chevanan,N., Rosentrater,K.A. and Muthukumarappan,K. (2010) Effects of processing conditions on single screw extrusion of feed ingredients containing DDGS. Food Bioprocess Technology 3: 111-120.

Fang,Q.,Hanna,M.A.andLan,Y. (2003b) Extrusion system design. In: Encyclopedia of Agriculture, Food and Biological Engineering (ed. D.R. Heldman). Marcel Dekker‘New York, pp. 306-309.

Harper, J.M. (1981) Extrusion of Foods, Vol. I. CRC Press, Boca Raton, FL .738 Handbook of Food Process Design: Volume I

Kokini, J.L., Chang, C.N. and Lai, L.S. (1992) The role of rheological properties on extrudate expansion. In: Food Extrusion Science and Technology (eds J.L. Kokini،C.-T. Ho and M.V. Karwe). Marcel Dekker, New York, pp. 631-653.

Lundblad, K.K., Hancock, J.D., Behnke, K.C., presstlokken, E. (2008) The effect of adding water into the mixer on pelleting efficiency and pellet quality in diets for finishing pigs. Anim. feed Sci. Technol.

Miller, R.C. and Mulvaney, S.J. (2000) Unit operations and equipment IV. Extrusion and extruders. In: Breakfast Cereals and How They Are Made, 2nd edn (eds R.B.Fast and E.F. Caldwell). American Association of Cereal Chemists, Inc., St Paul، MN, pp. 215-277. 
Reimer, L. (1992). Conditioning. In: Proc. Northern Crops Institute Feed Mill Management and Feed Manufacturing Technol. Short Course. P.7. California Pellet Mill Co. Crawfordsville, IN.

Riaz, M.N. (ed.) (2000) Extruders in Food Applications. Technomic Publishing، Lancaster, PA.

Rosato, D.V., Rosato, A.V. and DiMattia, D.P. (2003) Blow Molding Handbook, $2^{\text {nd }}$ edn. Hanser Gardner Publications, Cincinnati, $\mathrm{OH}$.

\section{الملخص العزبي}

العوامل المؤثرة علي جودة أعلاف الأسماك الطافية المنتجة بنظام البثق

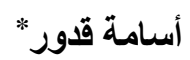

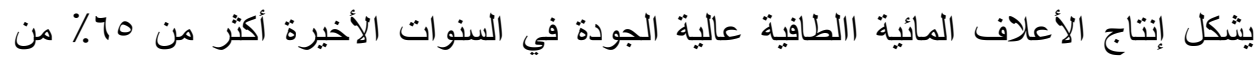

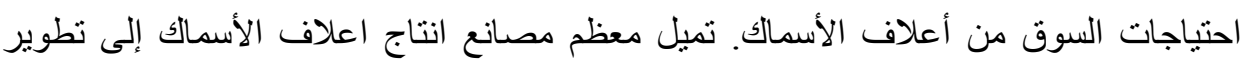

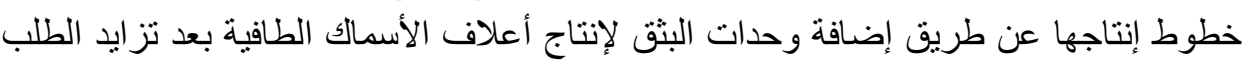

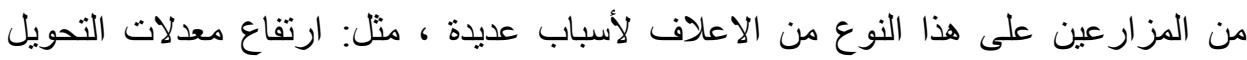

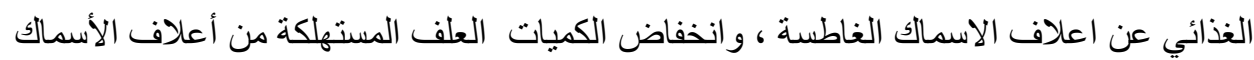

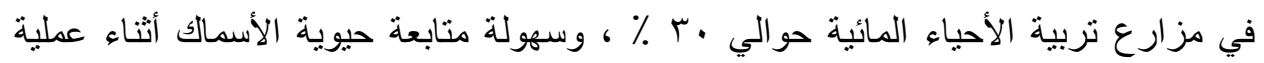
التخذية وخفض فرص الإصابة بأمر اض الأسماك.

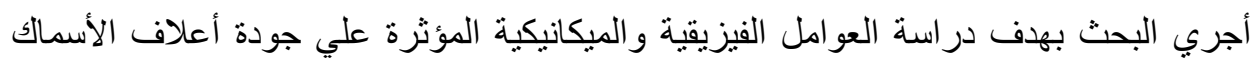

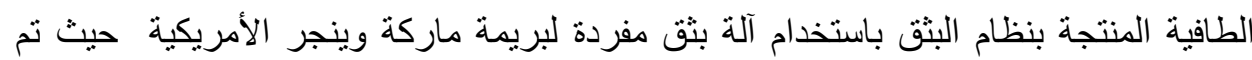

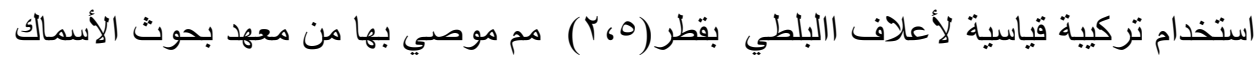

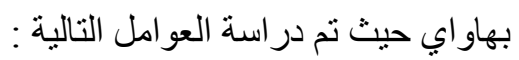

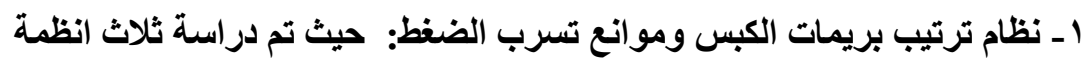
نظام ترتيب ذو قوي قص عالية وضغط مرتفع

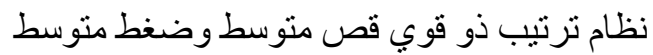

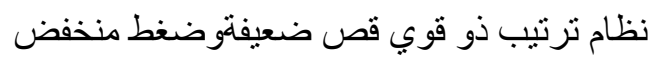

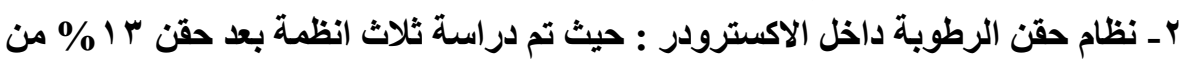
البخار في وحدة التهيئة لكل نظام

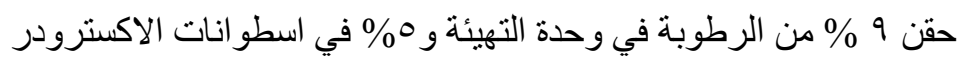
حقن § \\% من الرطوبة في وحدة التهيئة فقط

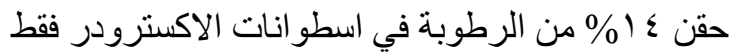

* استاذ مساعد الهندسة الزراعيةـ قسم العلوم الهندسيةـ كلية الثروة السمكية_جامعة السويس 
rـ نظام التجفيف والتبريد للاعلاف المنتجة : حيث تم دراسة نظامين

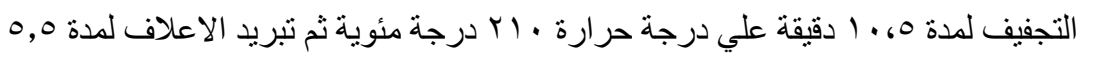

\section{دقيقة}

تبريد الاعلاف فقط بدون تجفيف لمدة 0,0 دقيقة

وقد اظهرتحليل النتائج العديد من المؤشر ات الأيجابية التي تساعد قطاع تصنيع اعلاف الاسماك من انتاج اعلاف اسماك طافية عالية الجودة ذات ثبات عالي في الماء وباقتصادية عالية عن طريق استخدام عوامل

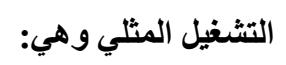

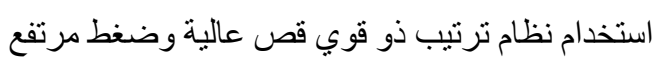

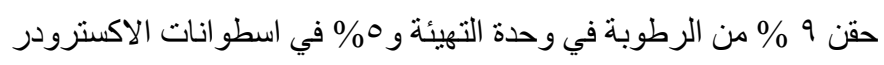

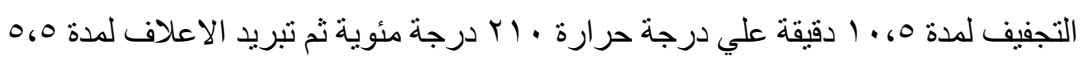
دقيقة وكاتت اهم النتائج باستخدام هذه العوامل هي : انتاجية للاكسترودر بو اقع 7، 97 ( كجم| ساعة - طاقة

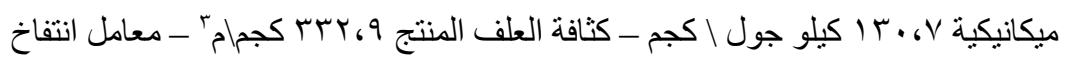

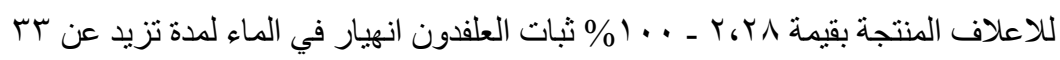
ساعة 